\title{
Potential Options to Optimize Therapy of Gastroesophageal Reflux Disease with Proton Pump Inhibitors
}

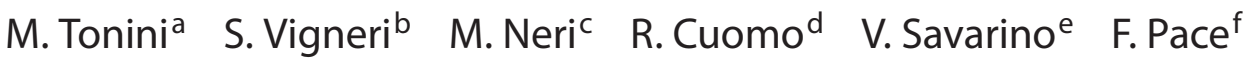 \\ a Department of Physiological and Pharmacological Sciences, University of Pavia, Pavia, ${ }^{b}$ Department of Internal \\ Medicine, University of Palermo, Palermo, ' Department of Medicine and Aging Sciences, Section of Internal \\ Medicine and Gastroenterology, G. D'Annunzio University, Chieti, d Department of Clinical and Experimental \\ Medicine, Gastroenterology, University Federico II, Naples, ' Department of Internal Medicine, GI Unit, University of \\ Genoa, Genoa, and ${ }^{\mathrm{f}}$ Division of Gastroenterology, L. Sacco Hospital, University of Milan, Milan, Italy
}

\section{Key Words}

Gastroesophageal reflux disease • Proton pump inhibitors • Therapy optimization

\begin{abstract}
Proton pump inhibitors (PPIs) are antisecretory agents that are widely used in the short- and long-term management of gastroesophageal reflux disease (GERD) to relieve symptoms, heal esophagitis, and prevent complications, such as strictures and Barrett's esophagus. The total healthcare costs of GERD are high, especially for maintenance treatment. Therefore, the choice of cost-effective therapeutic options is an ineluctable challenge for public health authorities, thirdparty payers, and patients. In some European Union countries, a recent trend of public health authorities is to promote the choice of less expensive PPIs, regardless of their antisecretory potency - this in spite of the evidence that newer PPIs provide superior symptom relief and esophageal erosion healing compared to earlier drugs. Several large clinical trials have demonstrated the superiority of esomeprazole over other PPIs at standard doses for both initial and continuous maintenance therapy in patients with moderate/severe erosive esophagitis. The non-erosive GERD poses a major challenge as this condition appears more frequently to
\end{abstract}

be less responsive to PPIs. The use of PPIs with the strongest antisecretory properties might reveal to be more adequate and cost-effective, particularly for this indication.

Copyright $\odot 2007$ S. Karger AG, Basel

\section{Introduction}

In Western industrialized countries, epidemiological studies indicate that approximately $40 \%$ of the adult population has typical symptoms of gastroesophageal reflux disease (GERD), such as heartburn and acid regurgitation [1], on a monthly basis. In a relevant proportion of subjects (from 7 to $20 \%$ ), the rate of symptom appearance is daily/weekly, thus rendering the underlying GERD a chronic acid-related disorder, with a significant reduction of the quality of life $[2,3]$. The prominent causative factors of GERD symptoms are gastric acid and pepsin (less frequently bile), which are present in the refluxate.

Because of their excellent antisecretory effect, proton pump inhibitors (PPIs) are currently considered drugs of choice for the treatment of GERD not only in the erosive form, but also in the form lacking any endoscopically demonstrable mucosal lesions (non-erosive reflux disease - NERD) [4]. This means that the choice of medical

\section{KARGER}

Fax +41613061234 E-Mail karger@karger.ch www.karger.com
(C) 2007 S. Karger AG, Basel

0012-2823/07/0764-0171\$23.50/0

Accessible online at:

www.karger.com/dig
Prof. M. Tonini

Department of Physiological and Pharmacological Sciences

University of Pavia, Piazza Botta, 11

IT-27100 Pavia (Italy)

Tel. +390382986 363, Fax +390382986 385, E-Mail tonini@unipv.it 
treatment of GERD is not primarily influenced by the results of upper gastrointestinal endoscopy but is driven by symptoms in clinical practice [2]. Despite their therapeutic success in the management of GERD, PPIs have limitations. These are the lack of sufficient acid control over the complete 24 -hour period with a single standard dose and their high cost. The current challenge in GERD is to optimize the therapy by adopting cost-effective strategies for uncomplicated forms of the disease with mild symptoms (e.g. the on-demand approach) $[5,6]$, for moderate/severe erosive esophagitis or NERD refractory to conventional PPI doses [7]. Thus, two strategies are to be implemented in clinical practice, e.g. a step-down approach for patients requiring long-term therapy [8], as well as the search of the maximal effective dose of antisecretory therapy in patients non-responding to conventional PPI dosing $[9,10]$.

We performed a structured electronic search of PubMed (from January 1988 to July 2007) by using the following index terms: gastroesophageal reflux disease, esophagitis, NERD, proton pump inhibitors, gastric acid inhibition/suppression, and therapy optimization.

\section{Treating GERD: Medical and Economical Considerations on a 'Major' Disorder}

Direct and indirect costs of GERD are high. The direct costs mainly refer to medical visits, diagnostic testing (gastroesophageal endoscopy, $\mathrm{pH}$-metry and $\mathrm{pH}$-impedance metry) and expenses for medications. The indirect costs of GERD, which are poorly characterized from a pharmacoeconomical point of view and which may be even higher than the direct costs $[11,12]$, are related to the social, familiar and economical impact of the disease, and include absenteeism and loss of workplace productivity, which are highly compromised in untreated GERD patients [13].

Concomitantly, also the health-related quality of life (HRQoL) is impaired by GERD symptoms [14], and this has a negative impact in the personal well-being, which is superior to that encountered in other chronic disorders, such as hypertension, mild congestive hearth failure, angina and conditions associated with menopause [15]. Therefore, an appropriate symptom control is the primary target when treating GERD, and this is optimally achieved by PPIs [3]. Additional goals in GERD therapy are the healing of mucosal damage, if present, and the prevention of GERD complications, such as strictures and Barrett's esophagus.

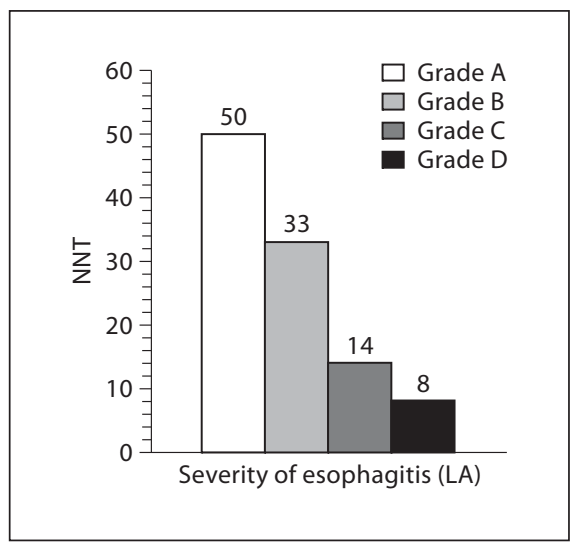

Fig. 1. Esomeprazole versus other PPIs in the erosive esophagitis healing. A meta-analysis of randomized clinical trials revealed that the number needed to treat (NNT) for esomeprazole decreases as Los Angeles (LA) grade of severity increases. In the presence of LA grade D esophagitis, the NNT for esomeprazole is 8 . This means that 8 patients would need to be treated with esomeprazole in lieu of an alternative PPI to achieve 1 additional case of healed esophagitis [adapted from 18].

Large clinical experience attests that PPIs are the most efficacious antisecretory agents, since they are able to heal esophagitis (and maintain remission) in up to 70$90 \%$ of patients, vs. $40-60 \%$ with $\mathrm{H}_{2}$-receptor antagonists $\left(\mathrm{H}_{2}-\mathrm{RAs}\right)$, following $4-8$ weeks of treatment $[16,17]$. Within the class of PPIs, there are differences in terms of healing rates among the individual drugs: a recent metaanalysis examining 10 studies including more than 15,000 patients with esophagitis has shown a 10\% (RR 1.10) and $5 \%$ (RR 1.05) relative increase in the probability of healing with esomeprazole versus alternative PPIs at 4 and 8 weeks, respectively [18]. At 8 weeks, there was an absolute risk reduction of $4 \%$ and the number needed to treat (NNT) was 25. In other words, 25 patients with erosive esophagitis would need to be treated with esomeprazole in lieu of an alternative PPI to achieve 1 additional case of healed esophagitis. The same study found that the effectiveness of esomeprazole was inversely proportional to baseline severity of esophagitis. The calculated NNTs by Los Angeles (LA) grade of erosive esophagitis (grades AD) were 50, 33, 14, and 8, respectively (fig. 1). Considering these data, the effectiveness of esomeprazole, although similar to other PPIs in mild forms of erosive disease, is higher in the more severe forms. In terms of symptom control, esomeprazole conferred an $8 \%$ (RR 1.08) relative increase in the probability of GERD symptom relief at 4 weeks [18]. Because of their superior therapeutic effectiveness, PPIs are currently considered drugs of choice for 
clinical management of GERD, not only in the erosive form but also in NERD. Since the control of NERD symptoms with PPIs is less efficient than that obtained in patients with reflux esophagitis [19], the use of drugs with modest antisecretory properties compared to PPIs might reveal an inadequate therapeutic option for NERD in many circumstances. Indeed, $45 \%$ of patients with NERD have a positive esophageal $\mathrm{pH}$-metry, while $37 \%$ of the remaining $55 \%$ of patients with negative $\mathrm{pH}$-metry is hypersensitive to acid infusion or to mechanical distension of the esophageal wall $[20,21]$. The management of patients with typical reflux symptoms, but with normal esophageal acid exposure/sensitivity, is more problematic, since they may have a non-acid-reflux, a functional disorder associated with altered gastric or esophageal motility [22], and/or psychosocial disturbances. It is in particular for this subset of patients that an optimal inhibition of acid would allow to clearly distinguish those with an acid-related disorder from those with other etiologies mimicking NERD.

There is preliminary evidence that a profound inhibition of acid secretion caused by PPIs may decrease dysplasia associated with Barrett's esophagus [23]. However, a decrease of the incidence of esophageal adenocarcinoma was not observed despite an extensive use of PPIs [24], suggesting that GERD itself, at variance with Barrett's esophagus, does not increase the risk of esophageal cancer [25].

The impact of PPI therapy on GERD-related extraesophageal symptoms also deserves attention, since a large number of pulmonary (asthma, bronchitis, fibrosis) and ENT symptoms (hoarseness, chronic pharyngitis, laryngitis, laryngeal cancer, chronic cough, dysphonia) as well as non-cardiac chest pain, sinusitis, obstructive sleep apnea have been described in association with GERD. While non-cardiac chest pain may improve very rapidly with the use of PPIs, pulmonary or ENT symptoms may require long treatments at higher dosages before any effect appears $[26,27]$. A clinical approach aimed at evaluating the best cost-effective diagnostic strategy for the treatment of gastroesophageal reflux associated with chronic persistent cough showed that the lowest cost is the strategy where PPI test is performed as first investigation [28]. In this context, recent studies indicate that a more effective suppression of intragastric acidity achieved with esomeprazole may result in a faster control of extraesophageal symptoms of GERD [29].

PPIs are the ideal drugs for an optimal management of all forms and clinical expression of GERD and, as a consequence, prescriptions of these drugs are escalating steadily worldwide; the expenses for PPIs are exceeding 10 billion dollars in the USA, where two PPIs are among the top five selling drugs [30]. Probably in response to this economic trend, in some European countries (e.g. Italy and Germany) national/regional/district health authorities aim at reducing the medical costs of treating GERD. Although not declared, a corollary of this campaign is (i) to completely neglect the issue of HRQoL in selecting a therapy against GERD, (ii) to deliberately underestimate the impact of indirect costs, and (iii) to focus only on the issue of reducing the cost of drugs, possibly by using antacids, histamine $\mathrm{H}_{2}$-RAs, or generic PPIs. This is a short horizon walk. If this strategy may be appealing for an apparent saving of public resources in the short term, in the long term it may unveil aspects of therapeutic inappropriateness with incorrect medical and economical consequences both for patients and social/familiar surroundings. Insufficient/inappropriate therapy may have particularly negative consequences in patients with severe esophagitis, such as the elderly [31-33], or those with severe symptoms with or without esophageal erosions, and may leave inadequately treated many patients with NERD.

The aim of current medical therapy in GERD is to first inhibit acid secretion with the most potent drug and then to tailor therapy for the individual needs of patients.

\section{Optimizing Therapy of GERD}

An extensive medical literature, dedicated symposia, and continuing medical education courses in acid-related disorders have contributed to improve the knowledge of primary care physicians on the various treatment modalities (both for acute and long-term therapy) to optimize the $\mathrm{pH}$ control in patients with GERD. Acute therapeutic strategies may vary according to the initial therapeutic approach, which is defined as step-up, step-down or step-in. The step-up approach consists of an initial therapy starting with compounds less effective in controlling $\mathrm{pH}$ (antacids, alginates or $\mathrm{H}_{2}$ - $\mathrm{RAs}$ ), and switching to the use of PPIs when necessary, whereas the stepdown approach consists of an initial use of PPIs with a subsequent reduction of their dosage [34-36]. These are pharmacoeconomic models that have been critically evaluated only in a limited number of studies, although the step-up approach is now considered the less cost-effective model for treating GERD and the clinically less appropriate [35]. In the clinical setting, it has been observed that the step-in approach (a therapeutic model that 


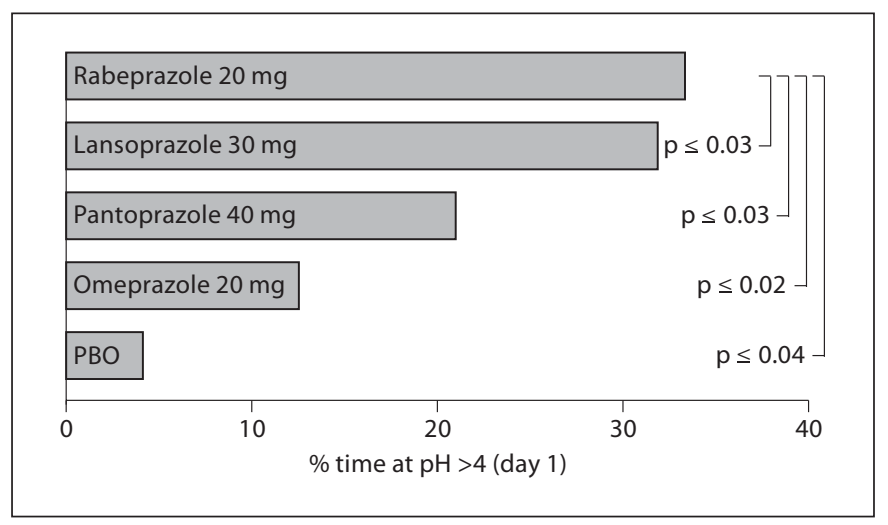

Fig. 2. Antisecretory properties of PPIs as assessed in three separate studies in healthy volunteers. Data refer to as mean \% time with an intragastric $\mathrm{pH}>4$ on day 1 of treatment (24-hour intragastric $\mathrm{pH}$ measurements). Note that the antisecretory effect of 20 $\mathrm{mg}$ rabeprazole is significantly higher than that produced by 30 $\mathrm{mg}$ lansoprazole, $40 \mathrm{mg}$ pantoprazole, $20 \mathrm{mg}$ omeprazole, or placebo $(\mathrm{PBO})$ [adapted from 42].

starts with and maintains a given dose of a PPI throughout the acute treatment of GERD) is the most effective approach in relieving symptoms and promoting healing of erosions, and also the economically most advantageous therapeutic model for GERD [37].

Independently from the acute therapeutic approach initially chosen, a long-term maintenance treatment is necessary in most patients, since GERD is a chronic relapsing disorder. In this respect, it is known that in the absence of a maintenance therapy the relapsing rate is $90 \%$ in patients with esophagitis and $75 \%$ in patients with NERD, after 6 months from the initial treatment [38]. Several approaches have also been described for maintenance therapy. They include continuous, intermittent and 'on-demand' therapy.

Continuous therapy with PPIs should be adopted by patients with erosive esophagitis with doses to be selected according to the individual response. In the vast majority of patients, half standard dose of PPI is sufficient to maintain the remission, although higher doses (including a b.i.d. regimen) are usually required for patients who initially had moderate/severe ERD [9]. Maintenance PPI therapy is well tolerated for up to 10 years of continuous use, and without apparent signs of tachyphylaxis [39]. A continuous use of PPIs is not necessary in many patients [8]. In a proportion of patients $(60 \%)$ with mild symptoms of GERD, several studies have shown that on-demand or intermittent therapy with PPIs is efficacious [40]. On-demand therapy is a patient-centered approach to GERD and a cost-effective one when PPIs are used [41]. The acceptance by the patient is good but the on-demand treatment should be transformed in a continuous one if frequent symptom breakthrough occurs, or more than 3 administrations per week become necessary. Obviously, symptom control achieved during the first day of treatment is a crucial target for the on-demand therapy. Figure 2 shows the antisecretory effect of single standard PPI doses during the first 24-hour monitoring [42]. Esomeprazole was not included in this cross-over study. Based on literature data, esomeprazole at standard dose $(40 \mathrm{mg})$ maintained an intragastric $\mathrm{pH}>4$ for a percent of time during the first $24 \mathrm{~h}$ ranging from 41.5 to $57.2 \%$ [43, 44]. Intermittent therapy is either a patient- or a physiciandriven approach and consists in alternating episodes of continuous treatment with therapy discontinuation until symptoms recur [45].

In spite of the recognized efficacy of PPIs in the management of acid-related disorders, a proportion of patients with GERD do not respond to PPI therapy adequately. The persistence of symptoms and/or esophagitis may depend on several causes, such as an inappropriate suppression of gastric acidity (due to non-compliance, inadequate dosage and dosing instructions, nocturnal acid breakthrough, and non-acid reflux), whereas an insufficient symptom relief may depend on all the above causes, or on the fact that symptoms are not related to reflux [46, 47].

\section{Are PPIs All Equal?}

\section{The Lesson Learnt from Randomized Controlled Clinical Trials}

For primary care physicians, the difference in the efficacy/potency of available PPIs in treating acid-related disorders is not easily apparent. Indeed, within the frame of the economic constraints regarding PPIs in some European countries, the opinion that all PPIs are equal is pushed forward by public health services [48]. The declared intent is to reduce the direct costs associated with the PPI prescription. Confusion partly stems from the fact that (i) PPIs are not marketed at the same standard doses (apart from a few exceptions), and this makes it difficult to compare directly their therapeutic efficacy in the absence of 'true' bioequivalence studies, and that (ii) clinical trials comparing head-to-head relative efficacy may have a variable design as to what concerns the size of enrolled patients and consequently their statistical power, as well as inclusion and exclusion criteria, primary and 
secondary endpoints. Obviously, all these variables influence the clinical outcome of a trial. An example is given by the comparison between esomeprazole ( $40 \mathrm{mg} /$ day) and pantoprazole ( $40 \mathrm{mg} /$ day) in the initial healing of esophagitis, whose severity is classified according to the LA scale. In a study in which 3,151 patients with esophagitis (LA score: A-D) have been enrolled, esomeprazole was superior to pantoprazole either at $4(+6 \%)$ or at 8 weeks $(+5 \%)$ of treatment independently of the initial severity of esophagitis. Furthermore, esomeprazole performed better than pantoprazole in healing the most severe forms of esophagitis ( $+11 \%$ : grade $\mathrm{C} ;+18 \%$ : grade $\mathrm{D})$ at 4 weeks [49]. Conversely, in a study in which $227 \mathrm{pa}-$ tients with esophagitis (LA score: B and C) have been enrolled, no difference has been found between esomeprazole and pantoprazole after 4 or 8 weeks of treatment [50]. In this respect, other two comparative studies - involving 5,241 patients in the first and 284 in the second - have shown that esomeprazole ( $40 \mathrm{mg} /$ day) is either superior to lansoprazole $(30 \mathrm{mg} / \mathrm{day})$ in healing esophagitis at 8 weeks $(+10 \%$ : grade $\mathrm{C} ;+18 \%$ : grade $\mathrm{D})$ [51] or that there is no difference between the two drugs [52]. With regard to maintenance therapy of GERD, $20 \mathrm{mg} /$ day esomeprazole has been found either superior or equivalent to 20 $\mathrm{mg}$ /day pantoprazole $[53,54]$ and superior to $15 \mathrm{mg} /$ day lansoprazole after 6 months of continuous treatment [ 55 , 56]. No long-term studies are available comparing headto-head esomeprazole and either rabeprazole or omeprazole.

Recently, it has been demonstrated that patients refractory to single PPI doses (e.g. lansoprazole $30 \mathrm{mg} /$ daily) can be effectively treated with two different strategies: either doubling the dose of the initial PPI or switching it to a more potent one, such as esomeprazole at standard $40 \mathrm{mg} /$ daily dose [57].

Finally, as mentioned before, the difference in the therapeutic outcome among PPIs is not perceived by primary care physicians, who usually treat patients with uncomplicated forms of GERD with mild symptomatology that respond equally well to the various agents [58]. Conversely, gastroenterologists tend to base their therapeutic strategies on objective targets (severity of endoscopically demonstrated esophagitis, esophageal $\mathrm{pH}$ measurements), which respond differently to the various PPIs. Therefore, one possible solution to relieve pressure from health authorities on the general practitioners to reduce PPI expenses could be to leave the prescription of more efficacious and expensive PPIs to the specialist alone.

Based on current clinical evidence, which is partly sustained by the weight of numbers (see above), esome- prazole is the most efficacious antisecretory agent [59] for the treatment of GERD. As a consequence, not all PPIs are equal.

\section{Pharmacology of Esomeprazole}

All of the currently available substituted benzimidazole PPIs are racemic compounds with the exception of esomeprazole, which is an enantiomerically pure PPI corresponding to the isomer S-omeprazole [60,61]. Although considered a purely commercial enterprise by non-specialized literature, the introduction of esomeprazole in the market has had positive aspects from pharmacological, regulatory and ethical points of view. Indeed, the 'abolition' of the R-isomer, the less active moiety of omeprazole undergoing an extensive first-pass metabolism by the CYP2C19 enzymatic system, avoids the purchase cost, the administration and the potential side effects of a much less relevant therapeutic compound compared to the S-isomer. A more favorable metabolism of esomeprazole leads to an increase in plasma AUC (esomeprazole, $20 \mathrm{mg} /$ day, shows an AUC which is almost doubled compared to omeprazole at the same dosage) [62], which in turn corresponds to increased amounts of the drug reaching the pumps in the gastric parietal cells. Indeed, esomeprazole $20 \mathrm{mg}$ /day exerts a superior intragastric $\mathrm{pH}$ control ( $\mathrm{pH} \geq 4$ ) compared to the same dose of omeprazole at 8,12 , and $16 \mathrm{~h}$ in patients with GERD [59]. As a consequence, esomeprazole has a superior bioavailability compared to omeprazole, reaching a value of $90 \%$ (the highest value among PPIs) with $40 \mathrm{mg} /$ day $[7,63,64]$. Furthermore, this dose has the most prominent antisecretory effect compared to other standard doses of PPIs, since it is able to maintain intragastric $\mathrm{pH} \geq 4$ for at least $14 \mathrm{~h}$ in a day [59], as observed at day 5 of treatment (fig. 3).

The superiority of esomeprazole compared to omeprazole raises the question of why the former compound has been marketed at the same or higher dosages (20 and 40 $\mathrm{mg}$ ) of the latter compound. Although this choice seems apparently illogical [65], it should be kept in mind that with the available dosages of PPIs it is not possible to reach the 'ceiling effect' [46], i.e. the maximal antisecretoy effect, ideally corresponding to gastric $\mathrm{pH} \geq 4$ for $24 \mathrm{~h}$. The antisecretory effect of PPIs, though influenced by pharmacodynamic, pharmacokinetic and biochemical properties of any single molecule, is a dose-dependent phenomenon. Recent findings suggest that to achieve a near-maximal antisecretory effect the use of PPI at $40 \mathrm{mg}$ t.i.d. is required, as observed in patients with Barrett's 


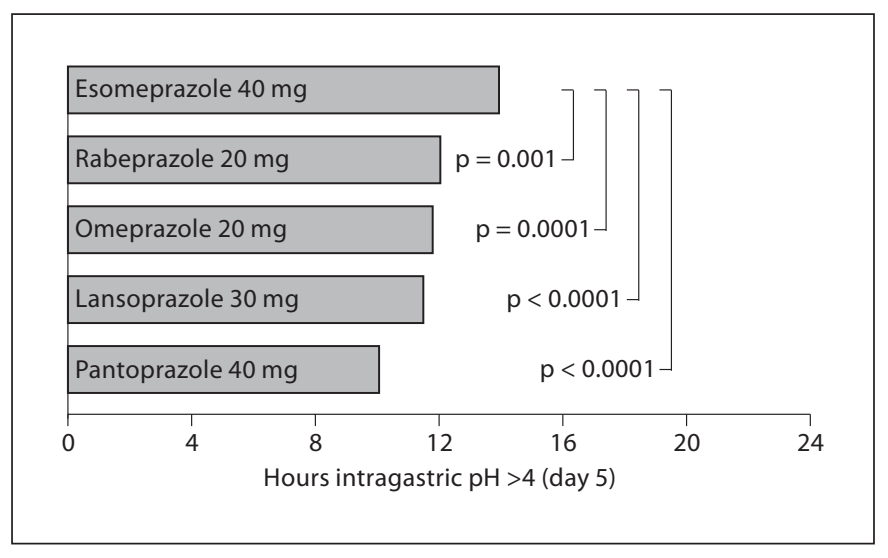

Fig. 3. Antisecretory properties of PPIs as assessed in a five-way cross-over study in Helicobacter pylori-negative patients with symptoms of GERD. Data refer to as mean number of hours with an intragastric $\mathrm{pH}>4$ on day 5 of treatment. The antisecretory effect of a standard dose of esomeprazole $(40 \mathrm{mg})$ is significantly higher than that produced by standard doses of rabeprazole $(20$ $\mathrm{mg}$ ), omeprazole (20 mg), lansoprazole (30 mg) and pantoprazole (40 mg) [adapted from 59].

esophagus [66]. This is the logical reason why esomeprazole has been marketed at the same or higher dosages than omeprazole in spite of a better pharmacokinetic and pharmacodynamic profile compared to the parent racemic compound.

\section{Conclusions}

GERD is a chronic relapsing disorder characterized by heartburn and acid regurgitation, which necessitates an adequate control of gastric acid secretion to relieve symp- toms, heal esophagitis, and prevent complications such as Barrett's esophagus and esophageal adenocarcinoma, particularly in patients with a prolonged and severe history of reflux.

For patients with GERD, acid suppressant therapy with PPIs remains a cornerstone of both short- and longterm pharmacological treatment. Despite impressive clinical outcomes compared to previous therapeutic options, there is still room for improvement by tailoring the therapy to individual needs in a cost-effective manner. Esomeprazole most profoundly suppresses gastric acid secretion and has been found to provide superior symptom relief and esophageal erosion healing in the most severe cases. Its use may be most suitable not only for initial and maintenance therapy in patients with more severe erosive esophagitis, but also in patients with NERD in order to differentiate those with an acid-related condition from those with heartburn of other etiologies. Also in the on-demand approach, PPIs as a whole and esomeprazole in particular, have shown to be useful in maintaining symptomatic remission in patients with NERD and/or mild esophagitis.

In spite of recognized effectiveness of PPIs, a proportion of patients with GERD do not adequately respond to drug treatment. The persistence of symptoms and esophagitis may depend on several causes, which primarily include an inappropriate suppression of gastric acidity (due to non-compliance, inadequate dosage and dosing instructions, nocturnal acid breakthrough), and to non-acid reflux. In the case of inappropriate acid control, a dose adjustment (e.g. with the use of higher single doses or a b.i.d. regimen) or the use of the most effective PPI is required in compliant, resistant patients.

\section{References}

1 Gallup Organization: Heartburn across America: a Gallup Organization national survey. Princeton/NJ, Gallup Organization, 1988.

-2 Devault KR, Castell DO: Updated guidelines for the diagnosis and treatment of gastroesophageal reflux disease. Am J Gastroenterol 2005;100:190-200.

-3 Moayyedi P, Talley NJ: Gastroesophageal reflux disease. Lancet 2006;367:2086-2100.

-4 Miner PB Jr: Physiologic and clinical effects of proton pump inhibitors on non-acidic and acidic gastroesophageal reflux. Aliment Pharmacol Ther 2006;23:25-32.
5 Inadomi JM: On-demand and intermittent therapy for gastroesophageal reflux disease: economic considerations. Pharmacoeconomics 2002;20:565-576.

-6 Talley NJ, Lauritsen K, Tunturi-Hihnala H, et al: Esomeprazole $20 \mathrm{mg}$ maintains symptom control in endoscopy-negative gastroesophageal reflux disease: a controlled trial of 'on-demand' therapy for 6 months. Aliment Pharmacol Ther 2001;15:347-354.

7 Horn JR, Howden CW: Similarities and differences among delayed-release proton pump inhibitors. Aliment Pharmacol Ther 2005;22:20-24.
8 Lee TJ, Fennerty MB, Howden CW: Systematic review: Is there excessive use of proton pump inhibitors in gastroesophageal reflux disease? Aliment Pharmacol Ther 2004;20: 1241-1251

-9 Tytgat GNJ: Management of mild and severe gastroesophageal reflux disease. Aliment Pharmacol Ther 2003;17:52-56.

10 Katz PO: Gastroesophageal reflux disease symptoms on antisecretory therapy: acid, non-acid, or no GERD. Rev Gastroenterol Disord 2006;6:136-145.

Tonini/Vigneri/Neri/Cuomo/Savarino/ Pace 
11 Jones MP: Acid suppression in gastroesophageal reflux disease: Why? How? How much and when? Postgrad Med J 2002;78:465468.

12 Sandler RS, Everhart JE, Donowitz M, et al: The burden of selected digestive diseases in the United States. Gastroenterology 2002; 122:1500-1511.

13 Dean BB, Crawley JA, Schmitt CM, et al: The burden of illness of gastroesophageal reflux disease: impact on work productivity. Aliment Pharmacol Ther 2003;17:1309-1317.

14 Wiklund I: Quality of life in patients with gastroesophageal reflux disease. Am J Gastroenterol 2001;96:S46-S53.

15 Dimenas E: Methodological aspects of evaluation of quality of life in upper gastrointestinal diseases. Scand J Gastroenterol 1993; 199:18-21.

16 Chiba N, De Gara CJ, Wilkinson JM, Hunt $\mathrm{RH}$ : Speed of healing and symptom relief in grade II to IV gastroesophageal reflux disease: a meta-analysis. Gastroenterology 1997;112:1798-1810.

17 Edwards SJ, Lind T, Lundell L: Systematic review: proton pump inhibitors (PPIs) for the healing of reflux oesophagitis - a comparison of esomeprazole with other PPIs. Aliment Pharmacol Ther 2006;24:743-750.

18 Gralnek IM, Dulai GS, Fennerty MB, Spiegel MB: Esomeprazole versus other proton pump inhibitors in erosive esophagitis: a meta-analysis of randomized clinical trials. Clin Gastronterol Hepatol 2006;4:14521458.

19 Dean BB, Gano AD Jr, Knight K, et al: Effectiveness of proton pump inhibitors in nonerosive reflux disease. Clin Gastroenterol Hepatol 2004;2:656-664.

20 Devault KR: The role of acid suppression in patients with non-erosive reflux disease or functional heartburn. Aliment Pharmacol Ther 2006;23:33-39.

-21 Shapiro M, Green C, Bautista JM, et al: Functional heartburn patients demonstrate traits of functional bowel disorder but lack a uniform increase of chemoreceptor sensitivity to acid. Am J Gastroenterol 2006;101:10841091.

22 Tonini M, De Giorgio R, De Ponti F: Progress with novel pharmacological strategies for gastroesophageal reflux disease. Drugs 2004; 64:347-361.

23 El-Serag HB, Aguirre TV, Davis S, et al: Proton pump inhibitors are associated with reduced incidence of dysplasia in Barrett's esophagus. Am J Gastroenterol 2004;99: 1877-1883.

24 Bytzer P, Christensen PB, Damkier P, et al: Adenocarcinoma of the esophagus and Barrett's esophagus: a population-based study. Am I Gastroenterol 1999;94:86-91.

-25 Solaymani-Dodaran M, Logan RF, West J, et al: Risk of oesophageal cancer in Barrett's oesophagus and gastroesophageal reflux. Gut 2004;53:1070-1074.
26 Malagelada JR: Supra-esophageal manifestations of gastro-esophageal reflux disease. Aliment Pharmacol Ther 2004;19:43-48.

27 Nord HJ: Extraesophageal symptoms: What role for the proton pump inhibitors? Am J Med 2004;117:56-62.

28 Baldi F, Cavoli C, Ghersi S, et al: Cost-effectiveness of different diagnostic strategies to assess gastro-oesophageal reflux disease in patients with unexplained chronic persistent cough in Italy. Dig Liver Dis 2006;38:452458.

29 Louis E, Jorissen P, Bastens B, et al: Atypical symptoms of GORD in Belgium: epidemiological features, current management and open label treatment with $40 \mathrm{mg}$ esomeprazole for one month. Acta Gastroenterol Belg 2006;69:203-208

30 Shaheen NJ, Hansen RA, Morgan DR, et al: The burden of gastrointestinal and liver diseases, 2006. Am J Gastroenterol 2006;101: $2128-2138$.

-31 Pilotto A, Franceschi M, Leandro G, et al: Clinical features of reflux esophagitis in older people: a study of 840 consecutive patients. J Am Geriatr Soc 2006;54:1537-1542.

32 Johnson DA: Gastroesophageal reflux disease in the elderly - a prevalent and severe disease. Rev Gastroenterol Disord 2004;4: S16-S24.

33 Hungin AP, Raghunath A: Managing gastroesophageal reflux disease in the older patient. Digestion 2004;69:17-24.

-34 Howden CW, Henning JM, Huang B, et al: Management of heartburn in a large, randomized, community-based study: comparison of four therapeutic strategies. Am J Gastroenterol 2001;96:1704-1710.

35 Habu Y, Maeda K, Kusuda T, et al: 'Protonpump inhibitor-first' strategy versus 'stepup' strategy for the acute treatment of reflux esophagitis: a cost-effectiveness analysis in Japan. J Gastroenterol 2005;40:1029-1035.

-36 Inadomi JM, McIntyre L, Bernard L, Fendrick AM: Step-down from multiple- to single-dose proton pump inhibitors (PPIs): a prospective study of patients with heartburn or acid regurgitation completely relieved with PPIs. Am J Gastroenterol 2003;98: 1940-1944.

37 Chang FY: Medical economy and acid reflux diseases. J Gastroenterol Hepatol 2006;21: S129-S132.

- 38 Carlsson R, Dent J, Watts R, et al: Gastroesophageal reflux disease in primary care: an international study of different treatment strategies with omeprazole. International GORD Study Group. Eur J Gastroenterol Hepatol 1998;10:119-124.

39 Bixquert M: Maintenance therapy in gastroesophageal reflux disease. Drugs 2005; 65: 59-66.

40 Bardhan KD: Intermittent and on-demand use of proton pump inhibitors in the management of symptomatic gastroesophageal reflux disease. Am J Gastroenterol 2003;98: S40-S48.
41 Pace F, Tonini M, Pallotta S, Molteni P, Bianchi Porro G: Systematic review: maintenance treatment of gastro-oesophageal reflux disease with proton pump inhibitors taken 'ondemand'. Aliment Pharmacol Ther 2007;26: 195-204.

-42 Pantoflickova D, Dorta G, Ravic M, et al: Acid inhibition on the first day of dosing: comparison of four proton pump inhibitors. Aliment Pharmacol Ther 2003;17:15071514.

43 Wilder-Smith CH, Claar-Nilsson C, Hasselgren $\mathrm{G}$, et al: Esomeprazole $40 \mathrm{mg}$ provides faster and more effective control than rabeprazole $20 \mathrm{mg}$ in patients with symptoms of GERD. Am J Gastroenterol 2001;96:S45.

-44 Thomson AB, Claar-Nilsson C, Hasselgren $\mathrm{G}$, et al: Esomeprazole $40 \mathrm{mg}$ provides more effective acid control than lansoprazole 30 mg during single and repeated administration. Gut 2000;47:A63.

45 Metz DC, Inadomi JM, Howden CW, et al: On-demand therapy for gastroesophageal reflux disease. Am J Gastroenterol 2007;102: 642-653.

46 Tytgat GNJ: Are there unmet needs in acid suppression? Best Pract Res Clin Gastroenterol 2004; 18:62-72.

47 Katz PO, Scheiman JM, Barkun AN: Acidrelated disease - What are the unmet clinical needs? Aliment Pharmacol Ther 2006;23:922.

48 Maestri E, Maltoni S, Formoso G, et al: Farmaci racemici ed enantiomeri. Identificare le novità realmente utili. Pacchetti Inform Farm 2006;3:1-4.

49 Labenz J, Armstrong D, Lauritsen K, et al: A randomized comparative study of esomeprazole $40 \mathrm{mg}$ versus pantoprazole $40 \mathrm{mg}$ for healing erosive oesophagitis: the EXPO study. Aliment Pharmacol Ther 2005;21: 739-746.

50 Gillessen A, Beil W, Modlin IM, et al: 40 mg pantoprazole and $40 \mathrm{mg}$ esomeprazole are equivalent in the healing of esophageal lesions and relief from gastroesophageal reflux disease-related symptoms. J Clin Gastroenterol 2004;38:332-340.

51 Castell DO, Kahrilas PJ, Richter JE, et al: Esomeprazole (40 mg) compared with lansoprazole $(30 \mathrm{mg})$ in the treatment of erosive esophagitis. Am J Gastroenterol 2002;97: 575-583.

52 Howden CW, Ballard ED, Robieson W: Evidence for therapeutic equivalence of lansoprazole $30 \mathrm{mg}$ and esomeprazole $40 \mathrm{mg}$ in the treatment of erosive oesophagitis. Clin Drug Invest 2002;22:99-109.

53 Labenz J, Armstrong D, Lauritsen K, et al: Esomeprazole $20 \mathrm{mg}$ vs. pantoprazole $20 \mathrm{mg}$ for maintenance therapy of healed erosive oesophagitis: results from the EXPO study. Aliment Pharmacol Ther 2005;22:803-811. 
54 Goh K-L, Benamouzig R, Sander P, et al: Efficacy of pantoprazole $20 \mathrm{mg}$ daily compared with esomeprazole $20 \mathrm{mg}$ daily in the maintenance of healed gastroesophageal reflux disease: a randomized, double-blind comparative trial - the EMANCIPATE study. Eur J Gastroenterol Hepatol 2007;19:205211.

-55 Lauritsen K, Deviere J, Bigard MA, et al: Esomeprazole $20 \mathrm{mg}$ and lansoprazole $15 \mathrm{mg}$ in maintaining healed reflux oesophagitis: Metropole study results. Aliment Pharmacol Ther 2003;17:333-341.

-56 Devault KR, Johanson JF, Johanson DA, et al: Maintenance of healed erosive esophagitis: a randomized six-month comparison of esomeprazole twenty milligrams with lansoprazole fifteen milligrams. Clin Gastroenterol Hepatol 2006;4:852-859.

57 Fass R, Sontag SJ, Traxler B, Sostek M: Treatment of patients with persistent heartburn symptoms: a double-blind, randomized trial. Clin Gastroenterol Hepatol 2006;4:5056.
58 Ragunath AS, Hungin AP, Cornford CS, Featherstone P: Use of proton pump inhibitors: an exploration of the attitudes, knowledge and perceptions of general practitioners. Digestion 2005;72:212-218.

59 Miner P Jr, Katz PO, Chen Y, Sostek M: Gastric acid control with esomeprazole, lansoprazole, omeprazole, pantoprazole, and rabeprazole: a five-way crossover study. Am J Gastroenterol 2003;98:2616-2620.

60 Tonini M, Vigneri S, Savarino V, Scarpignato C: Clinical pharmacology and safety profile of esomeprazole, the first enantiomerically pure proton pump inhibitor. Dig Liver Dis 2001;33:600-606.

61 Tonini M, De Giorgio R, De Ponti F: Nove therapeutic strategies in acid-related disorders. Expert Opin Ther Patents 2003;13: 639-649.
62 Lind T, Rydberg L, Kylebäck A, et al: Esomeprazole provides improved acid control vs. omeprazole in patients with symptoms of gastroesophageal reflux disease. Aliment Pharmacol Ther 2000;14:861-867.

63 Andersson T, Hassan-Ali M, Hasselgren G, et al: Pharmacokinetic studies with esomeprazole, the (S)-isomer of omeprazole. Clin Pharmacokinet 2001;40:411-416.

64 Hassan-Alin M, Andersson T, Bredberg E, Röhss K: Pharmacokinetics of esomeprazole after oral and intravenous administration of single and repeated doses to healthy subjects. Eur J Clin Pharmacol 2000;56:665-670.

65 Hellström PM, Vitols S: The choice of proton pump inhibitor: Does it matter? Basic Clin Pharmacol Toxicol 2004;94:106-111.

66 Spechler SJ, Sharma P, Traxler B, et al: Gastric and esophageal $\mathrm{pH}$ in patients with Barrett's esophagus treated with three esomeprazole dosages: a randomized, double-blind, crossover trail. Am J Gastroenterol 2006;101: 1964-1971. 